\title{
A inovação como fonte de vantagem competitiva em restaurantes temáticos de Brasília*
}

\section{Innovation as a source of competitive advantage in thematic restaurants in Brasilia}

Luciene Braz Ferreira ${ }^{1}$ Mabel Simone de Araujo Bezerra Guardia ${ }^{2}$ Sergio Ramiro Rivero Guardia ${ }^{3}$

* Recebido em: 03/11/2015.

Aprovado em: 21/03/2017.

1 Doutora em Administração da Universidade de Brasília em co-tutela com a Universidade Aix-Marseille, mestre em Engenharia de Produção pela Universidade Federal do Rio Grande do Norte (2005) e graduada em Administração pela Universidade Católica de Brasília (1999). Atualmente, é professora da Universidade Católica de Brasília (UCB) e do Centro Universitário de Brasília (UniCEUB). Tem experiência empresarial na área de Administração Financeira, com ênfase em custos e orçamento. Linha de pesquisa na área de inovação.

Agrícola na área de Construções Rurais e Ambiência (2012), mestrado em Engenharia de Produção pela Universidade Federal do Rio Grande do Norte (2006). Especialização pela Universidade Federal do Rio grande do Norte na área de qualidade, Programa em Engenharia de Produção (2000). Graduação em turismo pela Universidade Potiguar (1998). Experiência na área de Gestão da Qualidade e agenciamento atuação de mercado nas seguintes áreas: Companhias aéreas, Agências de viagens e Consultoria em gestão da qualidade aplicada a restaurantes e hotelaria.

Mestre em sistemas e computação na área de engenharia de software pela Universidade Federal do Rio Grande do Norte UFRN (2002). Graduado em processamento de dados pela Universidade Federal de Campina Grande UFCG (1987). Atualmente é engenheiro de sistemas e consultor em Tecnologias da Informação e Comunicação na DATANORTE (Companhia de Processamento de Dados do RN) e professor da Universidade Federal do Rio Grande do Norte (UFRN). Com larga experiência na área de sistemas de informação empresarial e assessoria na gestão de empresas; tendo participado na modelagem de processos de negócios e no desenvolvimento de sistemas computadorizados, atuando principalmente nas áreas de: Inovação, Gestão da TIC, Gerenciamento de projetos, Integração, desenvolvimento e implantação de sistemas de informação, Negócios eletrônicos, Sistemas de qualidade e mais recentemente em Marketing digital

\section{Resumo}

Este artigo procurou investigar a relação entre a inovação existente em três restaurantes em Brasília e a vantagem competitiva conquistada com base nessa inovação sob a óptica da Visão Baseada em Recursos. Para tal, foi realizada uma revisão da literatura sobre Visão Baseada em Recursos, gestão da inovação e inovação em serviços. Para a pesquisa prática, realizou-se um estudo de múltiplos casos em três restaurantes de Brasília utilizando-se a técnica de entrevista em profundidade e observação. A observação foi registrada por meio de fotografia e diário. As empresas tiveram resultados bem próximos. Os proprietários não dão ênfase à questão da concorrência e a administração do negócio, ainda, é insipiente. Como recursos raros, valiosos, não imitáveis e não substituíveis, foram citados os recursos mencionados como inovadores, tais como vista panorâmica, culinária diferenciada, matérias-primas únicas e, também, as combinações e música, o que leva a concluir que as inovações são, para esses restaurantes, uma fonte de vantagem competitiva sustentável, o que explicaria a durabilidade do negócio mesmo com uma administração não profissionalizada e um olhar apenas interno, sem considerar a concorrência. Espera-se com este estudo corroborar as pesquisas de inovação como estratégia sustentável.

Palavras-chave: Inovação. RBV. Vantagem competitiva.

\section{Abstract}

This article sought to investigate the relationship between the existing innovation in three restaurants in Brasilia and the competitive advantage gained from this innovation from the perspective of the Resource Based View. To this end, a review of the literature on Resource Based Vision, innovation management and service innovation was carried out. For the practical research, a study of multiple cases was carried out in three restaurants in Brasilia using the technique of in-depth interview and observation. Observation was recorded by means of photo and diary. The companies had very close results. Owners do not emphasize the competition issue, and business management is still insipid. As rare, valuable, non-imitable and non-replaceable resources, the resources mentioned as innovators, such as panoramic views, differentiated cuisine, unique raw materials and combinations and music have been cited, leading to the conclusion that innovations 
are , for these restaurants, a source of sustainable competitive advantage, which would explain the durability of the business even with an unprofessional management and an internal look only, without regard to competition. It is hoped that this study will corroborate innovation research as a sustainable strategy.

Keywords: PInnovation. RBV. Competitive advantage.

\section{Introdução}

Apesar das primeiras teorias da administração apresentarem uma visão apenas interna das organizações, as questões estratégicas sempre se apresentaram como importantes. A necessidade e o volume de informações, a cooperação entre equipes de trabalho e a satisfação do cliente, que a cada dia torna-se mais exigente, fizeram com que as organizações buscassem qualidade em todas as funções organizacionais, investissem na comunicação em todos os níveis de relacionamento existentes na cadeia de valor, focando a sustentabilidade do negócio e a maximização dos ativos. Em função do aumento de competição, as companhias têm procurado melhorar os seus sistemas de produção, suas relações com o mercado, enfim, otimizar sua eficácia global para tentar colocar-se à frente dos concorrentes. E, para isso, é importante que tenham seus objetivos bem definidos. Para tal, passaram a ser usados recursos tecnológicos, tais como intranets, extranets, websites, e-mails, dentre outros, além de investimentos em inovação tecnológica, que se tornaram primordiais.

A inovação passou a ser, também, considerada fator estratégico para as organizações, principalmente em ambientes altamente competitivos. Sua origem ocorreu no setor industrial, mesmo ponto de origem da produção em massa e a produção enxuta. Diante disso, muitos estudos foram realizados somente com esse enfoque. Gallouj e Weinstein (1997) afirmam que as teorias econômicas da inovação tenderam a ignorar os serviços ou, simplesmente, tratá-los como consequência da indústria. Vargas e Zawislak (2006) corroboram essa afirmativa ressaltando que na literatura o setor de serviços, constantemente, é tratado, apenas, como um reflexo da área industrial, não apresentando papel de destaque.

Dessa forma, este artigo propõe-se a estudar a inovação como ferramenta estratégica na área de serviços, mais especificamente em restaurantes com propostas inovadoras na cidade de Brasília, capital do Brasil.

\section{Vantagem Competitiva e a visão baseada em recursos}

A vantagem competitiva vem sendo estudada ao longo dos anos sob diversas perspectivas. Alguns teóricos (MINTZBERG, 1973; PORTER, 1986; COYNEY, 1986; DIERICKX; COOL, 1989; BARNEY, 1991; PETERAF, 1993) têm procurado explicar as razões pelas quais uma empresa consegue vantagem competitiva e, a partir desses estudos, buscam criar um modelo que ajude a predizer como uma organização pode ou, pelo menos, quais caminhos podem levá-la a conquistar essa vantagem.

Autores como Mintzberg (1973) e Porter (1986) possuem uma visão voltada para o ambiente externo, outros (DIERICKX; COOL, 1989, BARNEY, 1991; PETERAF, 1993) procuram explicações internas, nos recursos que as empresas já possuem. Lindelöf e Löfsten (2004) ressaltam que a vantagem competitiva é o resultado de uma compreensão profunda das forças externas e internas que afetam, fortemente, a organização. No entanto, em ambientes competitivos, é mais provável associar a rentabilidade com recursos e capacidades baseadas em vantagens de posicionamento do que com vantagens resultantes da seleção do segmento do mercado e da posição competitiva baseada em algum tipo de estratégia genérica.

Este artigo procura explicar a vantagem competitiva por meio de explicações internas, mais especificamente a Visão Baseada em Recursos (RBV). Na RBV, para Wernerfelt (1984) as organizações são um conjunto de recursos e capacidades que não podem ser compradas ou vendidas facilmente no mercado. Isso significa que a visão de competitividade está mais ligada a capacidades, competências, desenvolvimento humano e outros fatores intrínsecos à organização. Tido como fundamentais, os recursos determinam o sucesso de uma organização (PENROSE, 1959; BARNEY, 1991; WENERFELT, 1984);

Para um melhor entendimento, neste artigo será utilizada a conceituação de Wernerfelt (1984, p. 172) para recursos. Em sua visão, "recursos são qualquer coisa que pode ser pensada como uma força ou fraqueza de uma determinada empresa". Mais formalmente, os recursos podem ser definidos como aqueles ativos (tangíveis e intangíveis) que são amarrados, semipermanentemente, pela empresa como a marca, contatos comerciais, maquinário, procedimentos eficientes, capital, dentre outros.

Para Barney (1991), os recursos existentes nem 
sempre são estratégicos, ao contrário, poucos recursos são usados de forma estratégica pela organização. Para tal, o autor construiu um modelo que promove 4 características que um recurso deve ter para ser considerado estratégico, conforme quadro 1.

Quadro 1 - Características dos recursos

\begin{tabular}{|c|c|}
\hline Recursos & Descrição \\
\hline Valiosos & $\begin{array}{l}\text { Permitem a uma organização conceber estratégias que melhorem } \\
\text { sua eficiência e eficácia, aproveitando oportunidades e minimizan- } \\
\text { do as ameaças. }\end{array}$ \\
\hline Raros & Não são acessíveis a outros competidores. \\
\hline $\begin{array}{l}\text { Imperfeitamen- } \\
\text { te imitáveis }\end{array}$ & $\begin{array}{l}\text { Não é possível a outros competidores terem acesso ao recurso de } \\
\text { forma fácil. }\end{array}$ \\
\hline $\begin{array}{l}\text { Não substi- } \\
\text { tuíveis }\end{array}$ & $\begin{array}{l}\text { Não possuem um equivalente que não seja raro ou imperfeitamen- } \\
\text { te imitável. }\end{array}$ \\
\hline
\end{tabular}

Fonte: Adaptado de Barney (1991); Dierickx e Cool (1989).

Dierickx e Cool (1989) apresentam a argumentação de que a vantagem competitiva depende, basicamente, da facilidade com que os recursos podem ser imitados ou substituídos. Por último, os recursos não podem ser substituídos. Isso acontece quando não existem recursos capazes de implementarem as mesmas estratégias, ainda que de forma similar, ou quando seus resultados sucumbem às características que levam o recurso a ser gerador de valor estratégico. Os autores, ainda, apontam que o desenvolvimento interno dos recursos é essencial, visto que recursos não negociáveis que são desenvolvidos e acumulados pela firma defendem a imitação porque possuem dimensões tácitas e são socialmente complexos, eles surgem dos conhecimentos e da aprendizagem da organização.

\section{Gestão da Inovação}

A nova realidade econômica motivou as empresas a buscarem, urgentemente, maneiras de melhorar seu desempenho e minimizar gastos, utilizando a filosofia “fazer mais com menos". A ideia de produção em massa disseminada pelo fordismo começou a dar lugar ao conhecimento e a uma nova tendência tecno-econômica. Essa época foi marcada pela procura do saber em diversas instâncias. Esse conhecimento, num sentido econômico, diz respeito à produção de novos conhecimentos que deverão ser introduzidos e disseminados no sistema produtivo.

Um dos conceitos mais importantes em relação à inovação vem de Schumpeter (1982), que diz que a inovação surge na própria empresa, fomentada pelo desenvolvimento econômico do mercado ou do país. Em outras palavras, considera que inovação é tudo o que diferencia e cria valor para o negócio.

Na visão de Schumpeter (1982), não é usual que as inovações apareçam em resposta aos consumidores, apesar de o foco ser, sempre, agradá-lo e suprir suas necessidades. A ideia é que a inovação seja criada pela organização e difundida entre seus clientes, criando a necessidade pelo novo produto, serviço ou processo. $\mathrm{O}$ autor, ainda, afirma que "como regra, a nova combinação deve retirar os meios de produção necessários de algumas combinações antigas. [...] A realização das combinações novas significa, portanto, simplesmente o emprego diferente da oferta de meios produtivos existentes no sistema econômico" (SCHUMPETER, 1982, p. 50).

Partindo do princípio de que a inovação precisa trazer retorno foi criado o Manual de Oslo, desenvolvido pela Organização para Cooperação e Desenvolvimento Econômico (OCDE), que monitora, segundo Tigre (2006, p. 72), três tipos de inovação: “(i) produtos; (ii) processos; (iii) mudanças organizacionais. As informações abordam o comportamento inovador da empresa, os tipos de atividades empreendidas, os impactos percebidos e os incentivos e obstáculos à inovação".

Percebe-se que o Manual de Olso prega que, para se ter um produto tecnologicamente novo, ele deve diferir de tudo o que já foi produzido pela empresa. Esta é a mesma ideia empregada para a concessão de patentes, porém, a patente possui abrangência nacional e mundial, não fica restrita somente à empresa criadora.

\section{Método de pesquisa}

A pesquisa classifica-se como uma pesquisa descritiva, qualitativa e do tipo básica ou pura. Quanto ao método de pesquisa utilizado, escolheu-se o estudo de múltiplos casos. Foram realizadas entrevistas estruturadas em profundidade. As entrevistas ocorreram nos próprios estabelecimentos, sendo os sujeitos da pesquisa os proprietários e responsáveis pelo gerenciamento. Também foi utilizada a observação não participante, utilizando-se como meios de registro a fotografia e o diário. 
Os casos foram escolhidos com base no site Veja Brasília Restaurantes 2010/2011, o qual apresenta uma lista com 233 restaurantes de diversos bairros da cidade e de diversas especialidades. Foram escolhidos restaurantes que possuíam em sua descrição propostas inovadoras na concepção ou no tipo de alimentação servida. Ao final, três restaurantes aceitaram participar da pesquisa.

Para a análise dos dados, foram escolhidas dimensões apresentadas no quadro 1 .

Quadro 2 - Dimensões de análise

\begin{tabular}{|l|l|}
\hline Dimensões de Análise & Aspectos gerais considerados \\
\hline Especialidade & Faixa de Preços \\
\hline Tempo de existência & Localização \\
\hline Concorrência & Capacidade de atendimento \\
\hline Público-alvo \\
\hline Formão da organização & Existência do proprietário \\
\hline Classificação \\
\hline Custos \\
\hline Inovação & Treinamento \\
\hline Recursos de capital físico \\
\hline Recursos de capital humano \\
\hline Recursos financeiros e organizacionais
\end{tabular}

Fonte: Do Autor

Para os procedimentos analíticos utilizou-se a técnica de análise de conteúdo, com escolha prévia das categorias.

\section{Análise e Discussão dos Dados}

Para a Associação Brasileira de Bares e Restaurantes (ABRASEL), o mercado de restaurantes no Brasil tem crescido e possui um milhão de empresas, empregando 6 milhões de pessoas e movimentando 2,4\% do PIB nacional. As causas são diversas, porém, acredita-se que existe uma tendência de as pessoas fazerem suas refeições fora de casa, além da inserção da mulher no mercado de trabalho fomentar essa prática em dois sentidos: aumentar a renda familiar e a falta de tempo para cozinhar.

Em Brasília, esse mercado apresenta-se igualmen- se (2009), apesar da turbulência na economia mundial ocorrida em 2009, muitos investidores continuaram a investir nesse ramo no Distrito Federal. Segundo um levantamento do próprio jornal, os investimentos no setor passam de 519 milhões de reais e geram 4,7 mil empregos diretos e indiretos.

\subsection{Trem da Serra}

O restaurante Trem da Serra, inaugurado em 1995 na cidade de Sobradinho, cidade-satélite de Brasília, fica a $20 \mathrm{~km}$ do centro da cidade e tem foco em turismo rural ou ecoturismo. O restaurante foi fundado pela família Bravo no mesmo terreno onde está mora, tornando-se um empreendimento familiar. O local do restaurante era usado como sala de jogos da casa para receber amigos. A parte de marketing e administração ficou para o proprietário e a cozinha para sua esposa. Além do restaurante, a propriedade possui uma granja - Granja Nova Cambuci, com 35 anos de atividade na criação de galinha caipira, suínos, gado leiteiro, patos, pôneis e hortaliças. Atualmente, o restaurante é administrado pelo filho do casal, com formação na área de biologia e que usa seus conhecimentos para administrar a granja e inovar no restaurante.

Com capacidade de 150 lugares, sua culinária é focada na comida mineira e goiana. Além dos serviços de alimentação, o restaurante ainda oferece trilhas ecológicas, piscina e passeios de pônei para as crianças, além da visita à granja. Seu público-alvo consiste, basicamente, de famílias com crianças, moradoras na cidade e no Plano Piloto de Brasília. O restaurante é localizado no alto de uma serra, possuindo uma vista panorâmica da região florestal e parte da cidade de Sobradinho. Inicialmente a propriedade era apenas a casa dos proprietários e a granja, cuja produção era vendida em locais próximos. Quando o restaurante foi aberto, a granja passou a servir de fonte de matéria-prima e, ao mesmo tempo, um local para visitação dos clientes.

Na parte de produtos oferecidos os pratos são tradicionais, porém, com novos temperos e outras formas de preparo, o que faz com que seja acrescido algo inovador em cada um. Para o proprietário, também é inovador que o cliente possa ver a matéria-prima de preparo do prato em sua visita à granja. Os pratos possuem nomes que invocam o aconchego familiar como "Costelinha ao vovô Chico", "Pernil assado da vovó Neném" e "Franguinho de Terreiro com quiabo à Tia Anita”.

As novas ideias destes e de outros pratos surgem 
em conversas informais dos proprietários e em experiências na cozinha. Após testadas com amigos e familiares, que têm total liberdade para opinar, as inovações são passadas em treinamento para os funcionários da cozinha. Esses treinamentos são ministrados pelos proprietários.

Sobre a competitividade do restaurante, o proprietário afirmou que o restaurante não tem crescido nos últimos 5 anos, pelo contrário, houve uma retração. Com o falecimento do fundador, o restaurante parou de investir em divulgação, em novos pratos e nas próprias instalações. Há um ano as atividades foram retomadas e o restaurante ainda está no processo de reinvestimento, com novas ações de divulgação e reformas. Quanto aos concorrentes, na visão do proprietário, o restaurante possui, apenas, um concorrente direto, um outro restaurante de turismo rural localizado na mesma cidade-satélite.

Com relação aos recursos de capital físico, o restaurante não possui apoio tecnológico forte. Em termos de sistemas de informação, existe, apenas, um sistema de gestão financeira. A localização proporciona uma diferenciação porque, por ser afastado da cidade, o restaurante possui um ambiente de paz e tranquilidade, no qual as pessoas sentem-se em um lugar de descanso. Por outro lado, o proprietário ressaltou que essa distância, também, pode ser percebida como um fator limitador. $\mathrm{O}$ restaurante abre somente sextas, sábados e domingos, com maior movimento aos sábados e domingos, pois, no dia a dia, as pessoas não estão dispostas a dirigirem até lá. Ainda, para chegar ao restaurante, é preciso subir $3 \mathrm{~km}$ de estrada de chão, o que, também, dificulta o acesso.

Os recursos de capital humano são formados pelos relacionamentos duradouros e amistosos que os proprietários têm com fornecedores, clientes e funcionários. Os clientes podem sugerir e fazer reclamações diretamente ao garçom, porém, o proprietário disse que possui um tipo de ouvidoria informal, que é quem realmente faz a coleta de informações sobre a preferência dos clientes: uma senhora que vende doces caseiros à porta do restaurante aos sábados e domingos é quem realmente ouve as impressões e preferências dos clientes e repassa para o proprietário. Outro canal de comunicação é o site, no qual os clientes podem, inclusive, enviar e-mails para o proprietário com suas observações. A experiência dos funcionários é parte dos recursos de capital humano. Atualmente, são 2 funcionários na granja, 4 na cozinha e 3 garçons. No domingo existe um número maior, sendo uma pessoa na cozinha e mais 2 garçons. Os funcionários são, praticamente, os mesmos desde a fundação, com um relacionamento amistoso e, segundo um dos funcionários, são tratados não como se tivessem chefe, mas como se fossem da família. Ele completa dizendo que viu o proprietário atual crescer, o que torna o relacionamento ainda mais estreito.

A estrutura organizacional é dividida entre os dois proprietários. Um fica responsável pela parte financeira e o outro por todo o resto da administração. As decisões são tomadas pelos dois, tanto em termos de investimento, inovação, processos e administração de recursos humanos. Quanto ao planejamento, existe um planejamento formal das operações, estratégias e metas no início do ano, porém o proprietário afirmou que muito da administração ocorre por feeling, mesmo ele tendo feito cursos na área de administração.

\subsection{Servus}

O restaurante Servus foi fundado em 2003 pela família Fenzl. Localizado na cidade de São Sebastião, fica a $26 \mathrm{~km}$ do centro de Brasília, é gerenciado por duas mulheres, - mãe e filha - que possuem origem austríaca. A proprietária e administradora do restaurante é arquiteta e resolveu abrir o restaurante no espaço que antes era a casa do caseiro do seu sítio. Sua mãe é responsável pela parte financeira da administração. Devido à distância, o restaurante só abre aos sábados e domingos, servindo diversos pratos austríacos e alemães. No cardápio estão o tradicional chucrute, goulash, panquecas, eisbein desfiado, spätzle, uma diversidade de salsichas alemãs, mostarda, entre outros. O restaurante conta, ainda, com espaço para crianças e descanso. Atualmente, tem capacidade para 60 pessoas. O público-alvo é formado, basicamente, por famílias de descendentes europeus, pessoas que conhecem ou tem interesse em culinária europeia e funcionários de embaixadas de diversas localidades do mundo, não necessariamente sendo europeus.

Para a proprietária, o restaurante tem uma proposta inovadora desde a sua decoração: o Servus é decorado com objetos da casa da proprietária e de seus familiares. Podem ser vistos na decoração objetos europeus, inclusive um piano, quadros, pinturas, prataria e móveis do início do século passado. Outro diferencial citado foram as músicas alemãs e austríacas que ficam tocando ao fundo durante todo o período de funcionamento do restaurante. São músicas selecionadas pela proprietária e, segundo ela, acompanham a atmosfera dos clientes. Ela 
cita que, se percebe um casal namorando, coloca músicas mais suaves ou se, naquele dia, existem mais grupos considerados animados, a música, também, o é.

Os pratos, também, são considerados inovadores, mesmo sendo tradicionais da cozinha alemã. Novos temperos, novas formas de preparação são testadas e aplicadas, dando um toque particular à culinária. Também é colocado como diferencial o atendimento personalizado e o serviço de buffet. Como consequência, o atendimento personalizado torna-se fundamental para atingir-se tal objetivo. A proprietária fica durante todo o tempo de abertura do restaurante conversando com os clientes, explicando cada prato e sugerindo o que comer.

As inovações nos pratos surgem de testes em sua própria cozinha que, aliás, é estendida ao restaurante, ou seja, o restaurante possui uma típica cozinha de "casa", sem fogões ou equipamentos industriais.

Quanto à competitividade, a proprietária acredita não haver concorrente para o seu negócio por dois motivos: por ter o diferencial de servir como buffet e por estar num local afastado. Sobre o desempenho da empresa, com um ano e meio de inauguração, o restaurante já deveria ter sido ampliado e passado por reformas na cozinha, fato que até hoje não aconteceu, porém, mesmo assim, o movimento vem crescendo desde sua fundação. Um fator ressaltado pela proprietária sobre a questão do crescimento do movimento diz respeito a sua própria falta de formação na área. Segundo ela, este é um fator limitador, já que não possui nada formalizado em termos de planejamento, projeto de expansão ou mesmo divulgação.

O relacionamento com os fornecedores é considerado bom. Todos os produtos embutidos são comprados de fornecedores de São Paulo. As bebidas são compradas por meio de uma empresa importadora. As matérias-primas são, então, todas fornecidas externamente à empresa e para compras menores o atendimento é feito por supermercados. O restaurante, ainda, conta com uma linha de copos apropriados para cada tipo de cerveja, licor e outras bebidas.

Os funcionários seguem a linha, também, de "funcionários domésticos”. São as pessoas que trabalham na casa das proprietárias que trabalham na cozinha, duas ajudantes, dois garçons e uma lavadora de louça. Três colaboradores do restaurante residem no local. O relacionamento com os funcionários é o melhor possível, pois a proprietária acredita que os funcionários são a base da qualidade do restaurante. Também procura oferecer bons salários, por isso há pouca rotatividade.

\subsection{Las Paellas}

Fundado em 1991, o restaurante Las Paellas tem como foco a cozinha espanhola e outros pratos que buscam a fusão entre diversas culinárias. O restaurante fica localizado no Lago Norte, bairro de Brasília e faz parte da Cooperativa de Artesãos Moradores do Lago Norte (Quituart). A Quituart foi fundada em 2001 e tem como objetivo difundir a arte, a cultura e a gastronomia representativa dos seus cooperados e promover atividades específicas por meio de aprimoramento técnico-profissionais, sócio-culturais, educativos, esportivos, juntamente aos órgãos públicos e privados, entidades de classe, legações estrangeiras e instituições beneficentes. Por isso, o restaurante não possui uma sede exclusiva. Todo o espaço para recepção do cliente como mesas, palco e banheiros são compartilhados com todos os associados que possuem empreendimentos no local. Atualmente, o espaço possui capacidade para 600 pessoas, mas cabe ressaltar que o local é provisório. A sede oficial da cooperativa já existe e, ainda, está em construção. O estabelecimento é gerenciado pela única proprietária.

Segundo a gestora, sua clientela é formada por pessoas com faixa etária entre 45 e 60 anos, moradores do Lago Norte e com elevado grau de estudo, predominantemente pessoas acompanhadas da família (maridos, esposas, filhos e netos). Muitos são funcionários públicos e jornalistas. O local é informal e os clientes podem pedir bebidas num restaurante, refeição em outro e sobremesa num terceiro restaurante.

Para a proprietária, o que existe de inovador em seu restaurante é o cardápio, pois, apesar de ser um estabelecimento especializado em comida espanhola, vários outros pratos são servidos. Num primeiro momento, foram acrescidos ao cardápio pratos com diversos tipos de carnes: porco, pato, rã, ostra, avestruz, javali e polvo. Além disto, adotaram-se temperos de diversas partes do mundo, comprados em suas viagens internacionais ou mesmo pelo Brasil. A entrevistada, também, faz cursos de culinária durante as suas viagens e a partir dessas experiências são criados novos pratos. Sendo assim, as inovações são criadas por ela e pela família - marido e filhos - e os próprios clientes é que são as pessoas que opinam e sugerem modificações. Muitas dessas inovações necessitaram de novos equipamentos, o que, consequentemente, gerou custos.

Um fator limitador para as inovações são as matérias-primas. Alguns materiais não são encontrados em 
Brasília, como temperos mais refinados ou de algumas localidades do mundo. Em relação à competitividade, a gestora acredita que os outros cooperados são seus concorrentes diretos. Atualmente, são mais de quinze restaurantes. O relacionamento entre eles é amigável, principalmente pela própria estrutura de cooperativa e, no caso de um de seus clientes solicitar pratos que ela não possui no cardápio, outros restaurantes do Quituart são indicados.

Dos recursos tecnológicos, o restaurante possui um site que foi elaborado e tem a manutenção realizada por um de seus filhos. O restaurante aceita cartão de crédito e débito, porém, essa funcionalidade é evitada, sendo negociado com o cliente o pagamento em dinheiro.

Já as instalações são pequenas, porém bem organizadas. Para cada tipo de carne há uma tábua de cor diferente e o layout proporciona que o cliente, caso queira, possa acompanhar a preparação do prato. Quanto aos equipamentos, foi necessário comprar uma salamandra e uma panela de arroz japonesa para melhor preparar os alimentos e conservá-los. A proprietária também investe em vários tipos de cortadores, com diversos formatos.

O relacionamento com os clientes é bastante próximo, inclusive, a proprietária os chama de amigos e não de clientes. Muitos são seus "amigos" desde a fundação do restaurante. Alguns, inclusive, solicitam que ela os ensine a cozinhar ou a fazer pratos. Cabe salientar que o restaurante, também, faz pratos sob encomenda para jantares e eventos, normalmente pedidos pelos mesmos clientes que frequentam o estabelecimento nos finais de semana.

Quanto aos funcionários, o restaurante possui, apenas, duas funcionárias na cozinha. A proprietária é quem atende e serve as refeições. Quanto aos recursos financeiros e organizacionais, na parte administrativa, existe um contador que acompanha a parte financeira. A proprietária afirma que não possui qualquer formação na área ou sequer gosta de cuidar da administração. Muitos de seus projetos não foram implementados pela falta de um planejamento de execução. Seu foco e talento estão na parte de culinária, sendo esta sua verdadeira dedicação.

\subsection{Comparação entre os restaurantes}

Percebe-se que os restaurantes possuem estruturas similares. Todos os restaurantes possuem, em suas estruturas e histórias, similaridades uma vez que a base é de formação familiar. Em relação à concorrência, as visões são distintas, principalmente o restaurante Las Paellas. O público-alvo, apesar de ser distinto em relação ao res- taurante Servus, não demonstra disparidade entre os três, que primam por acolher famílias com crianças.

Quanto à inovação, todos os restaurantes acreditam que suas propostas de negócio são inovadoras em diversos aspectos. Para o Trem da Serra, a inovação está nas instalações, nos temperos de preparo da refeição e nos serviços agregados (piscina, pôneis e granja). Para o restaurante Servus, a inovação está nas instalações, decoração, música e atendimento. E, finalizando, para o Las Paellas, a inovação está nos temperos e carnes diferenciadas. Todas essas inovações podem ser classificadas como incrementais, pois não transformam radicalmente o serviço, porém acrescentam diferenciais que modificam essencialmente a prestação dos serviços. Conforme Sundbo e Gallouj (1998), a classificação dos três estudos de caso pode ser considerada inovação em produto.

$\mathrm{Na}$ análise dos recursos, é possível perceber que as três empresas possuem diversos recursos internos, sendo o mais falho a parte administrativa. Os recursos organizacionais não são considerados como prioridade e para a proprietária do Las Paellas ele é apenas uma obrigação. Com relação aos relacionamentos, apenas o relacionamento do restaurante Las Paellas se mostra complexo em relação aos fornecedores. Todos os outros relacionamentos são amigáveis. Um fato curioso é a percepção quanto aos concorrentes. Nenhum entrevistado declarou se preocupar com os concorrentes ou mesmo acompanhar o que fazem, como fazem e se estão com mais ou menos clientela. O restaurante Servus, inclusive, acredita que não possui concorrentes.

Para a análise dos recursos e sua classificação quanto a valor, raridade, imitabilidade e não substitutivos, pergunta feita como fechamento da entrevista, percebeu-se que todas as respostas levaram as inovações, conforme quadro 5 .

Quadro 3 - Quadro comparativo dos recursos estratégicos

\begin{tabular}{|l|l|l|l|}
\hline \multirow{4}{*}{$\begin{array}{l}\text { Recursos de } \\
\text { vantagem } \\
\text { competitiva }\end{array}$} & Trem da Serra & Servus & Las Paellas \\
\cline { 2 - 4 } & Visita à granja & Decoração típica & Receitas inovadoras \\
\cline { 2 - 4 } & Experiência (know-how) & Buffet & Carnes diferenciadas \\
\cline { 2 - 4 } & Leitão à Pururuca & $\begin{array}{l}\text { Servir à moda } \\
\text { austríaca }\end{array}$ & Clientela \\
\hline
\end{tabular}

Fonte: Do Autor

Portanto, os recursos inovadores são os considerados estratégicos, o que comprova que a inovação pode 
levar a organização a ter um diferencial competitivo. Somente o Las Paellas citou a clientela, que não foi citado, anteriormente, como um recurso inovador. Essas respostas corroboram a visão de Dierickx e Cool (1989) que os recursos que proporcionam vantagem competitiva devem ser desenvolvidos pela organização.

\section{Considerações finais}

A inovação possui papel fundamental na construção de riqueza de um país, sendo considerada como a "mola propulsora" de muitas economias. Assim, parte dos países em desenvolvimento tem investido em fomentar o desenvolvimento tecnológico, pesquisas e parcerias entre empresas privadas e institutos de pesquisa, tais como universidades. Porém, a inovação não ocorre, somente, de maneira planejada, com estudos prévios e formais. Ela, também, pode acontecer de forma empreendedora, na aplicação de ideias e invenções isoladas. Por isto, este estudo versou pela escolha de pequenas empresas e sua relação com a inovação.

Três restaurantes que se autointitulassem inovadores, com sede em Brasília, foram escolhidos. Procedeu-se a uma pesquisa com o intuito de identificar quais eram essas inovações e quais os recursos existentes na organização. Posteriormente, procurou-se cruzar as informações com as características de recursos que proporcionavam vantagem competitiva para a organização.

Portanto, este artigo procurou investigar a relação entre vantagem competitiva à luz da RBV e inovação. Percebeu-se que todos os elementos considerados inovadores eram, também, considerados valorosos, raros, não imitáveis e não substituíveis. E, numa observação mais minuciosa, pode-se, também, perceber que os recursos foram desenvolvidos internamente, com base no conhecimento e know-how dos proprietários dos estabelecimentos. Inclusive, todos afirmaram que suas inovações nos pratos, principalmente, são desenvolvidas pelos gestores com a ajuda de parentes e amigos. Sua aplicação só é divulgada para os funcionários da cozinha.

Mais pesquisas devem procurar analisar os tipos de recursos existentes nas organizações e comparar com os recursos ditos inovadores. É importante conhecer se nas aplicações a inovação pode, efetivamente, ser um diferencial competitivo ou é, apenas, mais um recurso necessário, porém, não estratégico, para as organizações.

\section{Referências}

BARNEY, J. B. Firm resources and sustained competitive advantage. Journal of Management, v. 17, p. 99-120, 1991.

DIERICKX, I.; COOL, K. Asset stock accumulation and sustainability of competitive advantage. Management Science, v. 33, n. 12, dez. 1989.

GALLOUJ, Faïz. Innovating in reserve and the attendant myths. SI4S Topical Paper, n.1, 1998.

GALLOUJ, Faïz. Towards a neo-Schumpeterian theory of innovation in services? Science and Public Policy, v. 24, n. 6, p. 405-420, 1997.

GALLOUJ, Faïz; WEINSTEIN, Olivier. Innovation in services. Research Policy, v. 26, p. 537-556, 1997.

GIOSA, Lívio Antonio. Terceirização: uma abordagem estratégica. São Paulo: Pioneira, 1997.

GOODE, W. J.; HATT, P. K. Métodos em pesquisa social. 3. ed. São Paulo: Cia Editora Nacional, 1969.

HAUKNES, Johan. Innovation in the service economy. Oslo: Step Group, 1996.

LINDELÖF, Peter; LÖFSTEN, Hans. Proximity as a resource base for competitive advantage: university-insdustry links for technology transfer. Journal os Technology Transfer, v. 29, p. 331-325, 2004.

PETERAF, M. The cornerstones of competitive advantage: a resource-based view. Strategic Management Journal, v. 14, p. 179-191, 1993.

ROZENFELD, Henrique et al. Gestão de desenvolvimento de produtos: uma referência para a melhoria do processo. São Paulo: Saraiva, 2006.

SCHUMPETER, Joseph Alois. Teoria do desenvolvimento econômico: uma investigação sobre lucros, capital, crédito, juro e ciclo econômico. São Paulo: Abril Cultural, 1982.

SUNDBO, Jon; GALLOUJ, Faïz. Innovation in services. SI4S Synthesis Paper, 1998.

TIGRE, Paulo Bastos. Gestão da inovação: a economia da tecnologia do Brasil. Rio de Janeiro: Elsevier, 2006. 
VARGAS, Eduardo Raupp de. A dinâmica da inovação em serviços: o caso dos serviços hospitalares no Brasil e na França. 2006. Tese (Doutorado em Administração) Pós-Graduação em Administração, UFRGS, Porto Alegre, 2006.

VARGAS, Eduardo Raupp de; ZAWISLAK, Paulo Antônio. Inovação em serviços no paradigma da economia do aprendizado: a pertinência de uma dimensão espacial na abordagem dos sistemas de inovação. RAC - Revista de Administração Contemporânea, v. 10, p. 139-159, 2006.
VARGAS, Eduardo Raupp de; ZAWISLAK, Paulo Antônio. A dinâmica da inovação em serviços hospitalares. In: BERNARDES, Roberto; ANDREASSI, Tales (Org). Inovação em serviços intensivos em conhecimento. São Paulo: Saraiva, 2007.

WERNERFELT, B. A resource-based view of the firm. Strategic Management Journal, v. 5, p. 171-180, 1984. 